\title{
Application of ERP System in Small and Medium-sized Tire Enterprise
}

\author{
Guangqiu Lu, a , Jiahui Liu ${ }^{1, b}$, and Fuling $\mathrm{Li}^{1, \mathrm{c}}$ \\ ${ }^{1}$ Mechanical and electrical Engineering college, Qingdao Binhai University, Shandong, China \\ a156360093@qq.com, b1193121893@qq.com, '602911490@qq.com
}

Keywords: ERP System; Tire Enterprises; Application

\begin{abstract}
ERP system is based on the ideas and methods of supply chain management, and the integrated information management system is developed on the basis of MRP II, it represents the development trend of management revolution of manufacturing enterprises in the information age. [1]ERP system has strong application values in the tire enterprise, its main purpose is to allocate and balance the enterprise's internal and external resources, coordinate the various administrative departments, carry out business activities under the market environment and improve the market competitiveness of the tire enterprise. Firstly, this paper introduces the main functions of ERP, then takes the tire enterprise as an example, analyzes the present situation and existing problems of information construction in the tire enterprise, and finally points out the measures of ERP system implementation.
\end{abstract}

\section{Introduction}

ERP is the abbreviation of Enterprise Resource Planning, which is established on the information technology and guided by a systematic management theory, is a kind of management platform used in decision-making for both policy-making level and common employees [2].

The managed objects of ERP are workshop equipment and other hardware resources and human resources, organizations and other software resources. Through the use of ERP system, Enterprises can complete the order with high quality on time, so as to maximize these resources, measuring financial risks accurately and then making efficient investment decisions may provide enterprises with competitive advantages and considerable profits.

\section{The Present Situation and Features of Our Country's Informatization Construction of Small and Medium Tire Enterprise}

The foundation of ERP system is the enterprise's information construction, at present, there are three main problems in the informatization construction of tire enterprises, most small and medium enterprise are lack of understanding for the significance of the information construction, informatization construction target is not clear, inadequate promotion efforts.

Lack of Understanding. In the promotion of the Internet, the informatization construction has become the trend of the times, enterprises informationization is not a marginal issue, But how to promote, how to speed up the process, But now some companies are lack of knowledge on this issue[3].The thought of enterprise leadership hesitation, they think that the management of information is a very abstract, very distant things, but also very troublesome thing, attitude is not very active; Some companies believe that the current benefit is good, not to be in a hurry to manage information construction; some think that the enterprise is poor, lack of talent, can not achieve management information. With this knowledge, enterprises lack the strength to promote the management of information, enterprise development information management system on the lack of depth.

Therefore, changing mind of enterprise managers is the premise of enterprise information construction [4].Enterprise managers should be aware that Informatization construction of small and medium tire enterprise is a very urgent matter, It is related to the long-term development of enterprises. 
The Target is Unclear. Many enterprises believe that the purpose of informatization construction is to improve labor efficiency, Instead of manual labor, improve the speed of information output, and these are just the primary stage of the enterprises informatization construction[5].In the process of informatization construction, many enterprises lack quantitative objectives, It is lack of in-depth study and Discussion on how to achieve the purpose of informatization construction, to achieve what kind of specific requirements, to achieve what function, and so on, are lack of in-depth study and discussion.

Inadequate Promotion Efforts. At present, some enterprises have recognized the value of informatization construction, have to purchase computer and computerized Accounting Software, Some companies think this is the enterprise information construction [6].in fact, this is very one-sided point of view; and many managers also have similar ideas, They take the office automation management and computerized accounting as the whole of the enterprise's informatization construction. Accounting informatization is an important part of enterprise informatization, but not all of it. Informatization construction requires the enterprise's information system to cover all the business of the enterprise, is system engineering.

\section{Construction Measures Of ERP System for Small and Medium-Sized Tire Enterprise}

In order to achieve the desired effect, the necessary measures should be taken for the construction of ERP system in tire enterprises, such as the support of senior leadership, select the appropriate ERP software, good staffing and training, etc.

Obtain the Support of Senior Leadership. ERP system is the advanced technology of enterprise operation and management, which plays an important role in the whole development of the enterprise [7]. ERP construction needs to invest a lot of manpower, material resources, financial resources, without the support of the supreme leader is unable to do. Top management needs to provide a good human resources and financial support for the comprehensive advancement of ERP. If there is no sufficient human resources and financial support, the construction and operation of the ERP system will be greatly affected, and the final effect will be not ideal.

Select the Appropriate ERP Software. Enterprises should analyze their characteristics and needs, select the appropriate ERP software, not the more advanced the better [8]. For SMEs, it is best to select medium-sized software products, so not only reduces costs, but also reduces the difficulty of construction of ERP systems; and software requirements for corporate officers is not very high, Relatively speaking, the function of the product is more comprehensive, the product can meet the need for standardization of enterprise management.

Good Staffing and Training. Enterprises should focus on different aspects of the ERP system construction, training staff in different positions, in order to avoid the problems caused by the lack of training, which can lead to system project delay and other issues. Training should be run through the whole process of ERP system. Each step in the implementation of the ERP system, the corresponding training should be carried out. The form of training can be varied, in addition to training, discussion, distribution of learning materials and reading, leading the relevant staff to visit the user, understanding the implementation of other enterprises can be used as a form of training, understanding the implementation of other enterprises, the above mentioned can be used as a form of training, the purpose is to enhance the effectiveness of training.

\section{Implementation and Application of ERP System in Small and Medium-sized Tire Enterprise}

Contracts and Purchase. Although the process of signing the contract and the purchase of software is relatively simple However, a different approach will produce different results, the ultimate aim is to use the lowest price to purchase a good product.

Therefore, enterprises should first select the software system model, and then the select the supplier, and arrange system suppliers for technical communication, The two sides should conduct business negotiations based on technology exchange, to determine the price and content of the contract. enterprises in addition to strive for the price, enterprises can also require suppliers to 
increase the spare parts, extend the system warranty period, increase training efforts, increase technical support, etc.

Installation, Commissioning and Acceptance. In order to meet the performance and operation of the system, installation location and route should avoid the strong magnetic field, high temperature and the place where people mix, and according to the requirements of the installation.

After the system is installed, commissioning work must be carried out, after the installation of the system is completed, it is necessary to carry on the debugging work, so that the system can be put into use in the best condition, and the personnel of the enterprise can correctly and skillfully grasp the operation method. The system debugging work done by suppliers, cooperate with the tire enterprises [9].

Supplier should deliver to enterprise a complete, correct and valid system, capable of accomplishing the technical targets specified in product description and specifications, as demonstrated by successful completion of the acceptance testing of the system. In the process of system debugging, firstly, single equipment installation debugging, and then the overall system test run.

System Maintenance and Upgrade. The maintenance and update of system are the basis for ensuring the normal and efficient operation of the system. ERP system maintenance, upgrade work:

(1)user rights management, including new user rights, permissions change, permissions, etc.;

(2)business process management, to assist the company's business department to develop the corresponding ERP business process;

(3)improve the company's ERP documents, including secondary development documents and technical support documents, etc.;

(4)the company's customer demand management, mainly preparing for the company ERP upgrade and transformation ;

(5)timely and effective communication with the software supplier, Feedback the customer's need to the software supplier in time, to prompt the software supplier to solve the problem in time, and to embody the will of the company to the next version of the software;

(6)routine maintenance of software, including database maintenance, data importing and exporting, the establishment of maintenance records documents, etc;

(7)the development and improvement of the ERP system reports, secondary development;

(8)the development and refinement of ERP management policies and processes;

(9)ERP data backups, including hard disk backup, CD backup, disaster recovery.

Business Processing. After the delivery of ERP system, in addition to the normal system maintenance and necessary upgrades, it mainly used for specific business processes, which are important and tedious works. In this stage, those software vendors and enterprises need to work together, enterprises need to make clear the responsibilities of relevant departments, enterprises need to Improve the organization and establish business processes, the information center can take charge of the infrastructure construction, master controlling room and the server, other relevant departments can arrange a full-time staff to take responsible for the department's operation debugging, so we can realize the centralized maintenance, the entire system as well as those relevant departments can be coordinated[10]. So this system can make timely feedback and handling when problems appear. After the completion of the basic settings, each module is enabled, all the basic data are entered into the computer, so that not only the actual operating level of business people are improved, but also these practical problems are solved. Then the man and machine run simultaneously for a period of time, the data test is consistent; the workstation will be allocated to the corresponding functional departments.

\section{Conclusion}

The purpose of the implementation of the ERP system is a relatively huge project, it cannot be completed overnight. The implementation can be carried out in phases on the basis of overall planning. Meanwhile, after the ERP system implementation, timely maintenance and upgrades are very important, only in this way, the system can play a greater role, and otherwise it will make the 
ERP system gradually become a vase decoration.

\section{References}

[1] Daryl Powell,Erlend Alfnes,Jan Ola Strandhagen.The concurrent application of lean production and ERP:Towards an ERP-based lean implementation process,Computers in Industry,vol. 64, pp. 8-9, 2013.

[2] Simona Stemad,Miro Gradisar,Samo Bobe.The influence of external factors on routine ERP usage.Industrial management \& data systems, vol. 111, pp. 4-5, 2011.

[3] OanaVelcu,Strategic alignment of ERP implementation stage:An empirical investigation.Information \& management, vol. 47, pp. 6-7, 2011.

[4] Yajiong Xue,Huigang Liang,William R. Boulton,Charles A. Snyder.ERP implementation failures in China: Case studies with implications for ERP vendors.International Journal of Production Economics, vol. 97, pp. 4-5, 2005.

[5] Vincent S. Lai,Connie K.W. Liu,Fujun Lai,Jian Wang. What influences ERP beliefs-Logical evaluation or imitation.Decision Support Systems,vol. 50, pp. 8-9, 2010.

[6] Hsueh-Ju Chen,Shaio Yan Huang,An-An Chiu,Fu-Chuan Pai.The ERP system impact on the role of accountants.Industrial management \& data systems, vol. 112, pp. 3, 2012.

[7] Chuck C.H. Law,Eric W.T. Ngai.ERP systems adoption: An exploratory study of the organizational factors and impacts of ERP success.Information \& Management,vol. 44 pp. 9, 2007.

[8] Bih-Ru Lea,Mahesh C. Gupta,Wen-Bin Yu. A prototype multi-agent ERP system: an integrated architecture and a conceptual framework. Technovation, vol. 25, pp. 4-5, 2005.

[9] Krumbholz,Maiden. The Implementation of Enterprise Resource Planning Packages in Different Orga-nizational and National Cultures, Information Systems, vol. 26 pp. 185 204.

[10]Arik Ragowsky,Toni M.Somers. Enterprise Resource Planning.Journal of Management Information Systems.vol. 19, pp.11-15, 2002. 